We thank Professor Ian Bone and Dr William Durward for giving their permission to publish these cases. The histopathological examinations were performed at the National CJD Surveillance Unit by Dr James Ironside.

Contributors: RdeS, JP, and DH raised the possibility of using single photon emission computed tomography as a diagnostic "pointer" in new variant Creutzfeldt-Jakob disease, and RdeS wrote the paper. AR, MT, and MZ discussed the core concept and suggested amendments to the early drafts. JP and DH reviewed the final manuscript. MT contributed psychiatric data in case 2, and AR interpreted the electrophysiological data. JP and DH interpreted the single photon emission computed tomograms. DH interpreted the other radiological studies and collated these with the single photon emission computed tomography scans. MZ was involved in establishing the final diagnoses.
Funding: None.

Conflicts of interest: None.

Will RG, Ironside JW, Zeidler M, Cousens SN, Estibeiro K, Alperovitch A et al. A new variant of Creutzfeldt-Jakob disease in the UK. Lancet 1996;347:921-5

2 Will RG, Zeidler M. Diagnosing Creutzfeldt-Jakob disease. BMJ 1996;313:833-4.

3 Will RG, Zeidler M, Brown P, Harrington M, Lee KH, Kenney KL Cerebrospinal-fluid test for new-variant Creutzfeldt-Jakob disease. Lancet 1996;348:955.

4 Hill AF, Zeidler M, Ironside J, Collinge J. Diagnosis of new variant Creutzfeldt-Jakob disease by tonsil biopsy. Lancet 1997;349:99-100.

5 Kirk A, Ang LC. Unilateral Creutzfeldt-Jakob disease presenting as rapidly progressive aphasia. Can J Neur Sci 1994;21:350-2.

(Accepted 21 July 1997)

\title{
Social alcohol consumption and low Lp(a) lipoprotein concentrations in middle aged Finnish men: population based study
}

\author{
Marita Paassilta, Kari Kervinen, Asko O Rantala, Markku J Savolainen, Mauno Lilja, Antti Reunanen, \\ Y Antero Kesäniemi
}

Department of Internal Medicine and Biocenter Oulu, University of Oulu, Kajaanintie 50, FIN-90220 Oulu, Finland

Marita Paassilta, research fellow Kari Kervinen, consultant physician Asko O Rantala consultant physician

Markku J

Savolainen,

associate professor

Mauno Lilja,

consultant physician

Y Antero

Kesäniemi,

professor of medicine

National Public

Health Institute,

Mannerheimintie

166, FIN-00300,

Helsinki, Finland

Antti Reunanen,

head of laboratory

Correspondence to:

Professor

Kesäniemi

antero.kesaniemi@

oulu fi

BMJ 1998;316:594-5
Light or moderate alcohol consumption decreases the risk of coronary heart disease. ${ }^{1}$ Beneficial changes in high density lipoprotein cholesterol concentrations are, however, observed at quite high levels of alcohol consumption-that is, $\geqslant 20$ units per week, 1 unit being 10-12 g. ${ }^{2}$ Therefore, other factors may be responsible for decreasing the risk of coronary heart disease when alcohol is consumed in social amounts. We studied the relation between light and moderate alcohol intake and $\mathrm{Lp}(\mathrm{a})$ lipoprotein concentrations. Lp(a) lipoprotein is an independent risk factor for coronary heart disease $\mathrm{e}^{3}$ and is affected by alcohol misuse. ${ }^{4}$

\section{Subjects, methods, and results}

We performed a population based cross sectional study of 300 men aged 40-60 years selected randomly by age stratification; $259(86 \%)$ participated in the study. Subjects were divided into four groups by alcohol consumption: abstainers (mostly lifetime teetotallers; 37 men) and three groups of drinkers. Drinkers in the lowest third consumed $<39 \mathrm{~g}$ alcohol/week (74 men), those in the middle third 39-132 g/week (75), and those in the highest third >132 g/week (73). Alcohol intake was ascertained from a questionnaire on the amount and quality of alcoholic beverages consumed during the previous two weeks. Plasma Lp(a) lipoprotein concentrations were determined by a two site immunoradiometric assay that showed a close correlation with two different enzyme linked immunoassays $(r \geqslant 0.96)$. Liver function was assessed by measuring lipid and enzyme concentrations in fasting blood samples using standard techniques. Statistical analysis was carried out with the SAS software package. The groups were similar for age and smoking habits. The body mass index, waist to hip ratio, systolic and diastolic blood pressure, and alanine aminotransferase values were highest in subjects in the third drinking
$>132 \mathrm{~g} /$ week compared with those in the two lower thirds and with non-drinkers $(\mathrm{P}<0.001$ for each parameter, analysis of variance). The mean concentrations of serum $\gamma$-glutamyltransferase increased with increasing alcohol intake - that is, 34, 33, 49, and $64 \mathrm{U} / 1$ respectively for teetotallers, and the lowest, middle, and highest third of drinkers $(\mathrm{P}<0.001)$. Blood glucose and serum insulin values did not differ between the groups. $\mathrm{Lp}$ (a) lipoprotein concentrations were higher (median, $206 \mathrm{mg} / \mathrm{l}$ ) in the teetotallers than in the drinkers. $L p(a)$ lipoprotein concentrations for the lowest, middle, and highest alcohol thirds were 137, 109, and $94 \mathrm{mg} / \mathrm{l}(\mathrm{P}<0.05$, Kruskal-Wallis test) (figure). As noted in other white populations, we observed a highly skewed distribution of $\mathrm{Lp}(\mathrm{a})$ lipoprotein concentrations and a wide range within the population. The ranges were similar in the study groups (figure). $\mathrm{Lp}(\mathrm{a})$ lipoprotein concentrations showed a weak but significant correlation with body mass index, waist to hip ratio, and insulin concentrations (Pearson's correlation coefficients $-0.15,-0.14$, and -0.15 respectively, $\mathrm{P}<0.025$ for each correlation). There were no significant differences in high density lipoprotein (means for the teetotallers, and the lowest, middle, and highest thirds of alcohol consumption $1.19,1.19,1.23$, and $1.27 \mathrm{mmol} / \mathrm{l}$ respectively) or low density lipoprotein cholesterol concentrations between the groups.

\section{Comment}

Our report shows that social drinking-that is, $<39 \mathrm{~g}$ alcohol/week or 1-4 units/week-is associated with low $\mathrm{Lp}$ (a) lipoprotein concentrations in middle aged men. No changes were observed in high density lipoprotein cholesterol or low density lipoprotein cholesterol concentrations, blood pressure, or liver enzyme concentrations. 


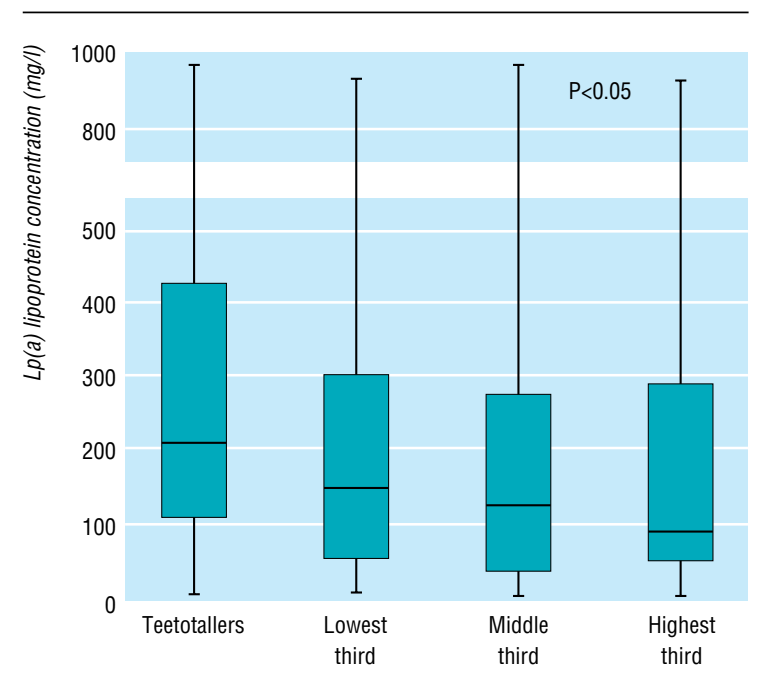

Plasma $L p(a)$ lipoprotein concentrations in four study groups. Boxes represent median and middle quarters of $L p(a)$ lipoprotein concentration and whiskers represent lowest and highest quarters

Other studies of alcohol consumption and $\mathrm{Lp}(\mathrm{a})$ lipoprotein cholesterol concentrations have dealt with differences between men and women, analysed alcohol intake qualitatively, ${ }^{5}$ and compared heterogeneous groups-that is, non-drinkers together with those who drink regularly on three or less days a week. To our knowledge, ours is the first study to show a relation between moderate alcohol consumption and $\mathrm{Lp}(\mathrm{a})$ lipoprotein concentrations. We conclude that low Lp(a) lipoprotein concentrations may be one factor explain- ing low mortality and retarded progression of coronary artery disease in social drinkers.

We thank Ms Saija Kortetjärvi, Ms Anna-Riitta Malinen, and Ms Liisa Laine for technical and secretarial support, and Markku Linnaluoto for help with the statistics.

Contributors: MP participated in data analysis, writing the paper, and a discussion of the core ideas. KK discussed the study hypothesis and core ideas, and participated in data analysis and writing the paper. AOR participated in the study design, patient investigations, and data collection. MJS discussed the study hypothesis and core ideas, and participated in writing the paper. ML participated in the study design, data collection, and writing the paper. AR participated in the study design, statistical analysis, and writing the paper. YAK was the principal investigator; he initiated and coordinated the formulation of the primary study hypothesis, designed the protocol, discussed core ideas, and participated in data interpretation and writing the paper. YAK will act as guarantor of the study.

Funding: This study was supported by grants from the Finnish Foundation for Alcohol Studies, the Finnish Foundation for Cardiovascular Research, and the Medical Council of the Academy of Finland.

Conflict of interest: None.

1 Rimm EB, Giovannucci EL, Willet WC, Colditz GA, Ascherio A, Rosner $\mathrm{B}$, et al. Prospective study of alcohol consumption and risk of coronary disease in men. Lancet 1991:338:464-8.

2 Haskell WL, Camargo C Jr, Williams PT, Vranizan KM, Krauss RM, Lindgren FT, et al. The effect of cessation and resumption of moderate alcohol intake on serum high-density-lipoprotein subfractions. $N$ Engl J Med 1984;310:805-10.

3 Bostom AG, Cupples LA, Jenner JL, Ordovas JM, Seman LJ, Wilson PW, et al. Elevated plasma lipoprotein(a) and coronary heart disease in men aged 55 years and younger. A prospective study. JAMA 1996;276:544-8.

4 Kervinen K, Savolainen MJ, Kesäniemi YA. A rapid increase in lipoprotein(a) levels after ethanol withdrawal in alcoholic men. Life Sci 1991;48:2183-8.

5 Nago N, Kayaba K, Hiraoka J, Matsuo H, Goto T, Kario K, et al. Lipoprotein(a) levels in the Japanese population: Influence of age and sex, and relation to atherosclerotic risk factors. Am J Epidemiol 1995;141:815-21.

(Accepted 24 June 1997)

\section{Drug points}

\section{Postural hypotension induced by paroxetine \\ C Andrews, G Pinner, Department of Health Care of the Elderly, Queen's Medical Centre, Nottingham NG7 2UH}

Antidepressant prescribing in elderly people is influenced by side effects and the patient's physical state. ${ }^{1}$ The high rate of falls and fractures in this age group may relate to antidepressant induced postural hypotension. ${ }^{2}$ Tricyclic antidepressants and monoamine oxidase inhibitors may produce postural hypotension, ${ }^{3}$ so treatment with selective serotonin reuptake inhibitors is often preferred in older patients. We report a case of postural hypotension induced by paroxetine.

A 75 year old woman who had had coronary artery bypass grafting six months previously was prescribed paroxetine for depression. The starting dose of $10 \mathrm{mg}$ was increased to $20 \mathrm{mg}$ after 14 days, but her other treatment (quinine bisulphate, fluvastatin, and temazepam) was unchanged. She continued to take paroxetine for 6 days, when she became dizzy and developed marked postural hypotension (blood pressure 170/90 $\mathrm{mm} \mathrm{Hg}$ while lying and $90 / 60 \mathrm{~mm} \mathrm{Hg}$ while standing). Physical examination and investigations, including a short tetracosactrin test, gave normal results. Paroxetine treatment was discontinued and her postural hypotension resolved. She agreed to a rechallenge test with paroxetine at a reduced dose of 10 $\mathrm{mg}$. Again, she developed dizziness and postural hypotension (blood pressure 140/90 mm Hg while lying and 110/
$60 \mathrm{~mm} \mathrm{Hg}$ while standing), which resolved on withdrawal of the drug.

To our knowledge, the only published report of postural hypotension associated with paroxetine relates to its increasing trimipramine concentrations when prescribed with trimipramine. ${ }^{4}$ At the time of writing, 43 cases of postural hypotension associated with paroxetine had been reported to the Committee on Safety of Medicines (personal communication). Other selective serotonin reuptake inhibitors have been reported to exacerbate syncope. ${ }^{5}$ Dizziness is cited on the datasheet for paroxetine, though not in relation to postural hypotension.

We suggest that postural hypotension should be considered if dizziness develops. The size of the postural fall in blood pressure seems to be dose related, and the dose should be reduced or drug treatment discontinued.

1 Katona C. Rationalizing antidepressants for elderly people. Int Clin Psychopharmacol 1995;10(suppl 1):37-40.

2 Dewan MJ, Huszonek J, Koss M, Hardoby W, Ispahani A. The use of antidepressants in the elderly: 1986 and 1989. J Ger Psychiatry Neurol 1992;5:40-4.

3 Warrington SJ, Padgham C, Lader M. The cardiovascular effects of antidepressants. Psychol Med 1989;suppl 16:40.

4 Leinonen E, Koponen HJ, Lepola U. Paroxetine increases serum trimipramine concentration: a report of two cases. Hum Psychopharmacol Clin Exper 1995;10:345-7.

5 Tandan T, Giuffre M, Sheldon R. Exacerbations of neurally mediated syncope associated with sertraline. Lancet 1997;349:1145-6. 